\title{
6 \\ Design-focused case studies in the professional discipline of public management
}

This book is centrally concerned with developing the professional discipline of public management. Part of developing any professional discipline is creating knowledge that can be used within professional practice. As theorized in this book, professional knowledge is an umbrella term for purposive theorizing and design-precedents. This book has focused on purposive theorizing until now; however, for the next two chapters, the focus will be on design-precedents and, in particular, on their formulation through design-focused case study research.

As design-focused case study research is a new term, it's useful to compare design-focused case studies with their stereotypical analogues in social science disciplines. The chief similarities between design-focused and stereotypical case studies are two-fold. First, their intent is to attain intellectual insight into theoretically-defined phenomena. Second, they consist in research projects, whose activities include topic-setting, issue-formulation, research design (including case-definition), analytical reporting, explanatory argumentation, and argumentation about theoretically-defined phenomena.

In comparison with stereotypical case studies, design-focused case studies are similar in that they feature argumentation about theoretically-defined phenomena. The difference is that the two kinds of case studies are concerned with different kinds of theoretically-defined phenomena. Whereas stereotypical case studies are concerned with theoretically-defined empirical phenomena, design-focused case studies are concerned with theoretically-defined purposeful phenomena. This difference relates to the disciplines within which case study research is done. Theoretically-defined empirical phenomena, like the price system or elections, are tied to social science disciplines, whereas theoreticallydefined purposeful phenomena, like machines, buildings, business firms, or public organizations, are tied to professional disciplines.

Stereotypical case study research projects are mechanisms for creating social scientific knowledge within a social science discipline. By analogy, designfocused case study research projects are mechanisms for creating professional knowledge within a professional discipline. The comparison requires a closer look at this complex analogy. The analogy is a close one insofar as both social science and professional disciplines provide contexts for case study research 
projects: for instance, a researcher pursuing any variant of case study research thinks of the meaning of the project at every step, with a view to presenting the study in the "context of justification," "whether in publications or in person. The demands for justification can also be substantively similar, even when a study's theoretically-defined phenomena relate to different forms of disciplines, as between social sciences and professional disciplines. Nevertheless, the analogy between design-focused and stereotypical case studies unravels to the degree that knowledge of purposeful phenomena differs from knowledge of theoretically-defined phenomena in the social sciences (a matter of some debate).

This chapter is designed to develop the idea of design-focused case studies, as it relates to the professional discipline of public management. For the most part, the chapter proceeds as if it's possible to talk intelligently about design-focused case studies without being much concerned about the strength or weakness of their analogy with stereotypical case studies. Proceeding this way makes sense for two pragmatic reasons. First, developing more definitive contrasts with stereotypical case studies will require much more discussion than can fit within this chapter, or this book. A reason for that view is that "stereotypical case studies" exhibit misplaced concreteness: their varieties are not as distinct as a rainbow's rays of color. Second, a key interest here is to see design-focused case studies as being different from lesson-drawing case studies, whether or not these are conducted and presented within a professional discipline.

In shifting the category comparison to these other case studies, the term "design-oriented" takes on a different meaning. That is, it doesn't mark the distinction between purposeful and empirical phenomena, because both lessondrawing and design-focused case studies are about the former. What's different is the whole idea of how to study purposeful phenomena within a professional discipline. Design-focused case studies bring mechanism-intent style purposive theorizing to bear in conducting research; they ask questions like: what is the phenomenon for, what does it consist in, and how does it work. Lesson-drawing case studies ${ }^{2}$ ask questions like: what happened, why did it happen, and how could a better result have been attained by following an existing professional theory of action in a more faithful and/or discriminating manner.

In pursuing questions about purposeful phenomena, design-focused case studies have something in common with lesson-drawing case studies. Both involve dialogues between cases and professional knowledge. But they have different lineage-based frames. Lesson-drawing case studies originate in casuistry, ${ }^{3}$ where the aim was to refine the practical judgment of individuals belonging to the same moral community, as discussed in Chapter 2. This intellectual practice was eventually picked up in professional disciplines, like law and business administration, and adapted accordingly. Design-focused case studies originate in professional disciplines akin to what Herbert Simon termed sciences of the artificial, including architecture and engineering. This intellectual practice has also been picked up in other professional disciplines, including management and public administration; it's more evident in some areas within these disciplines including operations management ${ }^{4}$ - than others.

This chapter is designed to help you make sense of the idea of design-focused 
case studies in public management. It's a challenge, similar to helping you to make sense of the whole idea of public management as a design-focused professional discipline. As the challenge is similar, so is the mechanism for tackling it. In what follows, you will encounter - and hopefully follow - a long conversation about this topic, one between two characters: You and Me. The conversation covers a lot of ground, beginning with the very idea of case studies. It builds on my earlier stated position about the same concept, then labeled as extrapolationoriented case studies (in following Eugene Bardach's lead). But it revises that position, by stressing the interplay between case study research and purposive theorizing within a professional discipline (here, public management), and by making a link between design-focused case study research about public organizations and design-precedents in fields like architecture. ${ }^{5}$

This chapter is something of a purposive theory of case studies within the professional discipline of public management. What it grossly lacks is a "design precedent" for doing such case studies. However, this deficit is addressed in Chapter 7, which reports a design-focused case study about a variant of public organizations, an international cooperation project. However imperfect it may be, the case study in the following chapter brings concreteness to the discussion of design-focused case studies; as such, the two chapters can just as profitably be read in reverse order as in the order in which they are actually presented.

\section{The dialogue begins}

You: What is a case study?

Me: Many theorists of case study research make claims about defining properties of case studies, but not everyone says the same thing. ${ }^{6}$

You: Doesn't everyone agree that case studies are a form of qualitative research? Me: No. Some theorists of case studies say that case studies can be quantitative. ${ }^{7}$ You: Maybe we should make the question about what people agree case studies aren't. And what they agree on is that they aren't a basis for generalization. Right?

Me: It's true that you're not going to find much encouragement from the literature on case studies to use them to generalize about populations of entities. But that doesn't mean that everyone agrees that case studies can't be used instrumentally.

You: Instrumentally, in relation to what end?

Me: Many defenders of case studies in the social sciences argue that they are for theorizing kinds of social phenomena.

You: Who has made these arguments?

Me: Probably the most well-known book author about case study research is Robert K. Yin. ${ }^{8}$ He said that, while case studies aren't suited to making statistical generalizations, they are suited to making analytic generalizations.

You: What's an analytical generalization?

Me: An analytical generalization is a research-supported statement about a kind of phenomenon, as long as the statement is not a generalization about a population of entities. 
You: Is the term "analytical generalization" in common use?

Me: Yes, for those who have read Yin's book. But the terms used to refer to research-supported statements about a kind of phenomenon tend to be specific to substantive traditions of inquiry.

You: Say more.

Me: The label used in processual sociology is "processes." The label used in historical sociology is "modest generalizations about historically-defined phenomena."10

You: What are examples of social processes?

Me: Group formation and disintegration, policy-making in government, and decision-making in organizations.

You: What are examples of historically-defined phenomena?

Me: Political revolutions, civil rights movements, and foreign policy crises.

You: What would be examples of authors and instrumental case studies, whether about processes or historically-defined phenomena?

Me: Albert Hirschman ${ }^{11}$ theorized social-economic reform, using the country case of Chile. Theda Skocpol ${ }^{12}$ theorized political revolutions, using the country cases of France, Russia, and Iran. Graham Allison ${ }^{13}$ theorized foreign policy crisis decision-making, using the case of the Cuban Missile Crisis, while Alexander George did the same on the basis of multiple case studies. Diane Vaughan ${ }^{14}$ theorized organizational decision-making cultures, first using the case of NASA and then using the case of U.S. air traffic control centers within the Federal Aviation Administration. Michael Barzelay and Raquel Gallego ${ }^{15}$ theorized public management policy-making, using the country cases of the U.K., Australia, Germany, France, Spain, Mexico, and Brazil.

You: Would they all have said they were making analytical generalizations?

Me: No, they'd use the language of their intellectual traditions. Accordingly, we should formulate and use a vocabulary that is appropriate to our discipline.

You: Alright. Shall I suggest some terms?

Me: I'd be grateful.

You: Design-oriented professional discipline of public management, public organizations, purposive theorizing, enterprise functions, mechanism-intent thinking, design-projects, sense-making, designing, argumentation, and dramatization. I realize it's a long list, and it doesn't provide an obvious label for "making analytic generalizations" from case studies.

Me: That's true. But there are some hooks here.

You: Other than public management and public organizations?

Me: Yes, purposive theorizing, mechanism-intent thinking, design-projects, and designing, for starters.

You: The only hook I see here is purposive theorizing, because of the word association between "theorizing" and "analytical generalizations."

Me: Let's work with that. If case study research in social science eventuates in analytical generalizations, then case study research in the professional discipline of public management eventuates in purposive theorizing. Purposive theorizing is a form of analytical generalizations, which is concerned with creating purposeful phenomena. Can you make some other connections? 
You: I know that purposive theorizing is supposed to channel the professional activity of designing, which is supposed to effectuate the designing scenarioprocess within design-projects. And I know that purposive theorizing is more useful to designing when it involves mechanism-intent thinking.

Me: Purposive theorizing establishes a kind of lineage of thinking about what public organizations are for, what they consist in, and what makes them work. It establishes mechanism-intent thinking as a style of purposive theorizing. But purposive theorizing does not provide a sufficient "context" for channeling the professional activity of designing. Something big is missing.

You: What's that?

Me: In a word, design-precedents.

You: What are those?

Me: A design-precedent is an account of an actually or historically existing purposeful phenomenon that addresses what it's for, what it consists in, and how it works in effectuating what it's for. Such accounts result from research within professional disciplines, whether arts of design or (to the extent they are different) sciences of the artificial. Such accounts are communicated with the intent of being available for adoption as reference points in design-projects.

You: That sounds like an interesting idea. Did you make up this term, or did somebody else do that?

Me: I came across the term in a book by the architect, Bryan Lawson, entitled What Designers Know. ${ }^{16}$ I have my notes on the relevant passages here on my tablet. Would you like me to read them out to you?

You: I'm all ears.

Me: Lawson wrote that, "Designers commonly and frequently make great use of what they often refer to as precedent. Precedents are often either whole or partial pieces of designs that the designer is aware of. ... Precedent is seen by designers as an important part of their knowledge upon which they are able to draw in a 'designerly way'. ... The early modern movement [in design] was a period in which precedent played an unusually minor role in what was thought to be a logical functionalist process. ... The post-modern world of design has rejected such a view. ... Precedent is such a vital, central, crucial feature of the design process that it plays a central role in all design education" (p. 96).

You: Is Lawson's view considered idiosyncratic in his field, whatever that is?

Me: Lawson is a professor of architecture and this book, like his others, fits within the literature on design studies. Ask any architect whether the precedent is important to their professional practice and the response will be unequivocally "yes."

You: I wonder why this idea of design-precedent didn't show up in this book before now.

Me: If it was going to come up, it would have done so in connection with Simon's idea of design-projects. But it didn't.

You: Why not?

Me: The whole issue of learning from experience wasn't central to Simon's scholarship; that was a major theme in the work of his one-time collaborator, James G. March. ${ }^{17}$ Simon is known for thinking that "domain knowledge" would 
channel analysis in designing - and that analysis would somehow channel synthesis. ${ }^{18}$ Simon didn't think of "domain knowledge" as consisting in designprecedents. I can't say what all the reasons for this were.

You: Okay, so what's the relationship between purposive theorizing and design-precedents?

Me: Would you want to take a crack at answering that question yourself?

You: Purposive theorizing and design-precedents are similar in what they are for. What they are mainly for is channeling the professional activity of designing. Me: And how are purposive theorizing and design-precedents different from each other?

You: I could use some help on this question.

Me: Fair enough. The principal role of purposive theorizing is to provide an approach to problem- and solution-structuring, while the principal role of design-precedents is to use experience as a basis for solution-structuring. Accordingly, they play complementary roles in designing.

You: Alright, then, purposive theorizing and design-precedents have distinct, complementary roles in designing. Would you say that they have different sources, as well?

Me: I'd prefer to respond to a more precise question, which compares the two.

You: Fine, if that's the way you want to be! Could I ask whether you would agree that purposive theorizing comes from critical engagement with past theorizing, while, by contrast, design-precedents come from case studies?

Me: It's a well-put question.

You: I know. And the answer is?

Me: I'd agree with both claims in your statement, but I would caution against the possible implication that case studies have no role to play in purposive theorizing. And I would also point out that, within professional disciplines like public management, purposive theorizing has a role to play in case study research, especially in framing the topic.

You: As to the unstated implication: I wouldn't have thought of denying that case studies have a role in debating approaches to public management.

Me: We are definitely on the same page. Incidentally, how do you think we should tell others about what we have been discussing here? How should we label case studies that are meant to become design-precedents, at least in part?

You: I presume you've thought about this before. What labels have you tried out?

Me: There was a time when I used the term "extrapolation-oriented case research." It's in the title of my 2007 article on the topic we're discussing now. ${ }^{19}$

You: Why would you have used that term?

Me: I was building on Eugene Bardach's 2003 presidential address at the Association of Public Policy and Management (APPAM), entitled "The Extrapolation Problem." ${ }^{20}$

You: And you don't use that term any longer?

Me: Correct. Not enough people have read Bardach's APPAM presidential address or my article building on it, for the term to bring instant meaning. Besides, I had become disenchanted with Bardach's presidential address for its 
sketchy treatment of designing, and I wanted to use the design studies literature - which I had come across after writing my 2007 piece - much more fully and explicitly.

You: So, what came next?

Me: At a workshop that I organized in 2015, I used the term "design-precedent case studies."

You: And how did that go?

Me: All of my workshop guests were very polite. Nobody complained. Afterwards, however, one of the attendees - who worked at the General Accountability Office (GAO) - told me that "design-precedent case studies" just wouldn't work, for the simple reason that, as nobody in my audience would know what a design-precedent is, they wouldn't begin to imagine what a designprecedent case study would be.

You: That participant seems to have been rather direct; perhaps it's because he worked at the GAO.

Me: The other explanation is that he's my cousin.

You: So where did you go from there?

Me: I gave a paper presentation in 2016 during a panel at the International Public Policy Association (IPPA) conference at the National University of Singapore's LKY School of Public Policy. I used the term "design-focused case study." Judging from the discussants' comments and other feedback, the audience seemed to like it.

You: I'm not surprised. The term isn't perplexing like design-precedent case studies. People will want to learn more about design-focused case studies. So, changing "precedent" to "focused" seemed to do the trick!

Me: I'm sticking with "design-focused case studies."

You: Can you point to examples of them?

Me: Do you remember visiting the mezzanine level of the Public Management Gallery?

You: Of course. I remember the displays on Simon's Sciences of the Artificial, ${ }^{21}$ van Aken and Berends' Problem-Solving in Organizations, ${ }^{22}$ and Barzelay and Campbell's Preparing for the Future: Strategic Planning in the U.S. Air Force. ${ }^{23}$

Me: Preparing for the Future contains design-focused case studies, although the term does not appear there; it was published back in 2003.

You: Any other examples?

Me: From my own research, yes. My study of the management system within the Brazil in Action program.

You: How about anybody else's work?

Me: When I introduce design-focused case studies in teaching, I typically use work by the late Judith Tendler of MIT. The case was about a massive state-wide rural primary health program, known as the Health Agents Program, that was created and operated in the Brazilian northeastern state of Ceará, back in the 1980s. The publications were an article in World Development, co-authored by Sara Freedheim, ${ }^{24}$ and a chapter in Tendler's Good Government in the Tropics. ${ }^{25}$ The case study showed that the Health Agents Program was successful, even though (and in some ways, because) it consisted in organizational arrangements 
that deviated from the incumbent theories of organization design in government, based on rent-seeking theories. Drawing on what the authors called the industrial performance literature, the case study also examined how the Health Workers Program neutralized dilemmas that were characteristic of mass social programs in settings where populations were hard to reach, public financial resources were limited, and mayors operated clientelistic networks.

You: That sounds like an interesting study. What was the take-away lesson?

Me: Why do you think it offered one?

You: It would seem to be a natural expectation of a case study about management.

Me: That is true.

You: Are you saying that design-focused case studies do not offer take-away lessons?

Me: I am saying that insofar as design-focused case studies offer design-precedents, they do not offer take-away lessons. Insofar as design-focused case studies do offer take-away lessons, then they are engaging in purposive theorizing.

You: How would you go about dissociating the idea of a design-precedent from the idea of a lesson?

Me: To dissociate design-precedents from lessons, we need to uncover why the idea that case studies are for lesson-drawing is so natural.

You: It's so natural to me, I don't think I can help much in that.

Me: A standard way to de-naturalize an association is to provide some history. In this situation, history would be about the discipline of management. Do you remember the discussion of the Harvard approach and the Fayolian background, in Chapter 2?

You: Vaguely. I remember that funny word, casuistry.

Me: Recall that casuistry is a method of practical argumentation within a moral community, one that involves wrestling with decision dilemmas. ${ }^{26}$ The method uses a form of the case method to train people in developing their faculty of judgment and their ability to provide reasons for their decisions, when they face decision dilemmas.

You: How is that relevant here?

Me: It's only relevant as background. The more directly relevant history is the idea of decision-making, which is taken to be the principal mechanism for performing an enterprise's management function.

You: That sounds natural, but I guess it's something we have to critically examine.

Me: Yes, what does decision-making in organizations consist in?

You: Well, I'd guess some mixture of thinking and communicating, within a context where roles are differentiated organizationally.

Me: Good. Now how do thinking and communicating fit together into a single human practice?

You: Is that where casuistry comes back in?

Me: Yes, in that casuistry is a method of practical argumentation that consists in both thinking and communicating.

You: Has anyone made the case that practical argumentation is a key activity within decision-making in organizations? 
Me: Yes, Charles Perrow ${ }^{27}$ interpreted March and Simon's original work on organization theory, back in the late $1950 \mathrm{~s},{ }^{28}$ precisely along these lines, in a chapter entitled "Neo-Weberian synthesis" in his Complex Organizations: A Critical Essay.

You: Alright, but what's the connection between decision-making and practical argumentation, on the one hand, and "lessons" and cases, on the other?

Me: Cases are typically presented as the basis for lessons. Decision-making and purposive theorizing are also straightforwardly connected. Purposive theorizing channels decision-making activity in organizations. Purposive theorizing is a main source of explicit premises in practical argumentation. Connecting the dots: cases are a basis for lessons that endorse or critique the purposive theorizing, which, in turn, channels decision-making in organizations.

You: So, this is why people would think that case studies would always offer a take-away lesson?

Me: It's an important part of the story, yes.

You: So, are you against presenting take-away lessons from design-focused case studies?

Me: I've learned not to be.

You: Learned?

Me: Yes, from referee comments on design-focused case studies that I've submitted for publication. So now I try to meet that expectation, and then try to exceed it by also providing design-precedents.

You: Why aren't referees satisfied with case studies that present design-precedents? Me: Because they believe, or pre-suppose, that decision-making effectuates the management function of enterprises. They subscribe to March and Simon's organization theory; they have not taken fully on board Simon's theory of design-projects and his associated argument about sciences of the artificial, that, by contrast, design-projects, with their irreducible element of designing, effectuates the management of enterprises. If they did, and if they were aware of the centrality of the idea of design-precedent within the literature on design studies, matters could be different.

You: That sounds like a deep problem. How can it be tackled?

Me: For me, it has been by writing Public Management as a Design-Oriented Professional Discipline.

You: Has anyone else tried to tackle this problem, in public management?

Me: Yes, Eugene Bardach, an outstanding professor of public policy at Berkeley. His first explicit attempt to do so was back in 1993, in a commentary piece within a symposium section of an issue of the Journal of Policy Analysis and Management. ${ }^{29}$ It was entitled, "Comment: the problem of best-practice research."

You: Did Bardach come out as for, or against, best practice research?

Me: Bardach agreed with the idea of what best practice research would be for, but he had strong reservations about what best practice research consisted in. He didn't think it worked, the way it was usually done. He made his argument by reconstructing a case study publication that he admired, indicating how it could exemplify the sort of best practice research he thought ought to be done. 
You: Oh, what case study publication was that?

Me: It was a book entitled, Breaking Through Bureaucracy: A New Vision for Managing in Government, published in 1992 by University of California Press. ${ }^{30}$ You: I think I've heard of the title before. Who wrote it?

Me: Me.

You: I should have known.

Me: Obviously.

You: What did you think of Bardach's "Comment"?

Me: I liked it very much, and I still do.

You: What did you like most?

Me: I liked the fact that he set the question of how to analyze practices within a public organization in such a way as to reveal how they work as functioning wholes and how they relate to generic challenges that are not specific to time and place. Eventually I came to see that Bardach was onto something important - so much so that it would change how I do my teaching and research.

You: When was that?

Me: An important milestone was the publication of Bardach's presidential address to the Association of Public Policy Analysis and Management in 2003, entitled, "The extrapolation problem." It was published in $2004 .{ }^{31}$ It is an inspiring piece. I've used it in my teaching routinely since then. It's the reading my former students say they remember most. Some of these students say they reread it every six months not to forget it.

You: That's impressive. What was the beautiful idea?

Me: Start with the overall issue, which is a practical question. If you're a professional practitioner in Jefferson County and you're asked to look into how a given program works in Washington County as a step toward solving a problem in your county, what approach would you take?

You: What's the answer to this practical question?

Me: The answer was presented in two parts: what shouldn't be your approach, and what should be. You shouldn't just describe the observable features of a program in a "source site," like Washington County, because that description even if detailed - will give you no more than a superficial understanding of how the program works there. You should seek insight into what causes the program's attractive characteristics in the source site. As you seek such insight, remember that you can only infer causes. You need theory to infer causes. You can get insight into how a program works in a source site by formulating an explanatory argument in which behavioral and/or social mechanisms play causal roles.

You: So, what are you supposed to do with this insight when it comes time to replicate the source site program in Jefferson County?

Me: Replicate social mechanisms; adapt features.

You: That's concise!

Me: Yes, that is how a student of mine expressed the take-away message. What do you understand it to mean, based on what we have been discussing here?

You: I gather that Bardach's message is partly a negative one: don't replicate features. I take that to mean that there's no reason for Jefferson County to copy Washington County's program, even if Jefferson County wants to replicate it. 
Me: You'd have some reason to replicate a feature if you have reason to think that it plays a causal role in Washington County's program.

You: But I thought that features don't play causal roles, only mechanisms do.

Me: Wrong! That's a misunderstanding of mechanism-based explanation. In general, actually existing conditions do play causal roles in social entities and processes, but you need theory to gain insight into how.

You: Oh, I guess I was getting confused by this mixing of vocabulary from social scientific explanation and from the arts of design. I feel a little embarrassed.

Me: Don't be. Let's get back to the idea of replicating mechanisms, while adapting features. What does it mean to adapt a feature?

You: It seems like it means that you should introduce program features in Jefferson County that are similar but not identical to those in Washington County.

Me: Similar in what way?

You: I guess that they should be similar in their effects, even if they are dissimilar in what they consist in.

Me: Good! But "similarity in effect" is not like similarity in object characteristics, like color.

You: What would you call two features that have different object characteristics, but are exactly the same in their effects within a purposeful phenomenon?

Me: I'd call them functional equivalents. And it's not just me who would use that term! The underlying idea is that of equifinality. You can get the same effects with different features. It's an important principle to consider when you're designing.

You: So what does Bardach mean by "adapt features"?

Me: You tell me.

You: If you have reason not to replicate a feature observed in Washington County's program - say for reasons of cost or acceptability - then specify a different feature in Jefferson County, provided that this different feature will be functionally similar.

Me: And what would make a different feature similar in a functional way?

You: It would have to play a similar causal role.

Me: Can you be more specific?

You: It would combine with a behavioral and/or social mechanism to produce a similar or identical effect.

Me: That's the general idea, yes. So restate the argument, please.

You: It's often infeasible, or unacceptable, for a source site's program features to be copied in a target site. Therefore, don't try to replicate program features. Take a different approach. Consider the principle of equifinality: you can attain functional equivalence without object equivalence. You can't apply this principle, however, without understanding how the program works within the source site. Fortunately, you can gain insight into how a program has worked, by studying how features "combine" with behavioral and/or social mechanisms. When designing a program for a target site, work with the idea of creating a different combination of features and social mechanisms than in the source site, but with the social mechanisms being the same in the target site as in the source site. In a phrase: replicate social mechanisms; adapt features. 
Me: Well done! Is there anything you think about Bardach's position that ought to be clarified?

You: I have some doubts about the idea that programs consist in features and social mechanisms and also about the idea that attractive program characteristics are due to how features and social mechanisms are combined.

Me: Fine, but first tell me what you find unproblematic, so we can pinpoint the issue.

You: Sure. I'm ok with the idea that programs consist in a multiplicity of features. I'm ok with the idea that some features are functionally and causally linked to others. Therefore, I'm ok with the idea that programs consist in combinations of features, because that statement sums up the two previous ones. But I don't know if I understand the idea of combinations of mechanisms.

Me: I can illustrate the idea with the case of a simple machine and its physical mechanisms.

You: What machine is that?

Me: A water filter jug. One physical mechanism is surface tension in liquids, specifically water. That mechanism plays a causal role in the movement of water from a tap into the jug's filter, keeping the surrounding area dry. Another physical mechanism is gravity. That mechanism plays a causal role in the downward movement of the water through the filter and into the basin, yielding filtered water ready for pouring into a container for drinking. The water jug works because of the combination of the physical mechanisms of surface tension and gravity.

You: Neat example. How do you explain that the idea of combinations of mechanisms applies outside the world of machines.

Me: If you want to read a thoughtful discussion about combinations of mechanisms in social explanation, I would point you to Diego Gambetta's chapter in an edited book with the title Social Mechanisms: An Analytical Approach to Social Theory. ${ }^{32}$

You: I think it's time to discuss the relation between features and behavioral and/or social mechanisms, particularly now that we realize that saying they "combine" is not very helpful. Did Bardach make clear what he saw as the condition-theory relation?

Me: Well, the piece was a bit brief on this issue, as it was essentially the text of his APPAM presidential address. But you could read an article entitled, "Learning from second-hand experience: methodology for extrapolation-oriented case research," published in Governance in 2007. ${ }^{33}$

You: Would you recommend that?

Me: I think it's a good piece, but I am biased.

You: How so?

Me: I wrote it.

You: And you're still happy with it, so many years later?

Me: I still find a lot to agree with. And I'm pleased that it's been cited a fair amount and that it has helped to spark interest in the discussion you and I are having now. You: What do you agree with, and what are your reservations now?

Me: The main thing I did was to try to push Bardach's ideas about what programs consist in a bit further, by blending them with some basic theoretical ideas of 
processual sociology. Bardach's ideas included program features and behavioral and/or social mechanisms. Processual sociology's vocabulary includes context, activity, and social mechanisms.

You: Tell me a little more about how context, activity, and social mechanisms fit together in processual sociology.

Me: Activity is what individuals, collective actors, and machines do. Activity is temporally and spatially located. Activity consists in lines of action.

You: What does activity affect?

Me: Activity affects conditions in social entities and processes.

You: Are there patterns in activity and its effects on social entities and processes?

Me: We have a vocabulary to speak of such patterns, with scenario-processes being one term. Scenario-processes are constituted by activity. Scenarioprocesses eventuate in scenario-outcomes. Scenario-outcomes are reflections of the effect of scenario-activity on social entities and processes.

You: Is this vocabulary specific to "processual sociology"?

Me: No. Processual sociology takes process philosophy and adds the vocabulary of spatio-temporal location, actors, context, and events. ${ }^{34}$ It also adds mechanisms, ${ }^{35}$ but that's not unique to processual sociology either. It's been emphasized even more so in analytical social theory. ${ }^{36}$ For present purposes, however, we can identify social mechanisms with processual sociology.

You: Can we return to the blend of language from design and processual sociology? How do you put them together?

Me: In the Governance article in 2007, I stated that activity within a program is influenced by process design features and process context factors. Both can be initial conditions and both can be conditions that are present during a stream of activity. The idea was that programs are constituted by process design features on purpose, while process context factors are present for other reasons.

You: Is it true that process context factors can be constitutive of a program, even when they are not there on purpose?

Me: Great question. I'm going to say "yes" to make the point that many of the conditions that are constitutive of a program or other purposeful phenomenon are (metaphorically) assembled rather than custom-made. Shifting metaphors, a given purposeful phenomenon is inevitably located within some socioecological context, and some of the conditions in that context will be part of the phenomenon. Take the machine example of the filtered water jug. A process context factor would be having potable water on tap, whereas a process design feature would be the handle on the jug.

You: So, the take-away here is that in processual sociology, scenario-outcomes eventuate from a combination of context and activity, while in public management, scenario-outcomes eventuate from a combination of process design features and process context factors, on the one hand, and activity, on the other.

Me: Good. Stated differently, the main idea is that processual sociology provides an intellectual tradition for theorizing a social phenomenon's context-activityoutcome dynamics, for the sake of advancing the discipline of sociology. The same intellectual tradition can be used to theorize purposeful phenomena that relate to public organizations, including programs. A step toward using that 
tradition to theorize purposeful phenomena is to adjust the vocabulary, with the idea of "context" in processual sociology being considered analogous to the idea of process context factors and process design features in public management.

You: Could you clear up something for me? Earlier in the book, you wrote about mechanisms as playing intent-fulfilling roles in an enterprise. As you've presented Bardach and processual sociology, mechanisms seem to be theories that are applied in understanding how a purposeful phenomenon works. I find it confusing to hear the term mechanisms being used in these two ways. Please help.

Me: You should mainly think of mechanisms as playing intent-fulfilling roles in an enterprise. As you do so, you will be engaging in purposive theorizing, in a mechanism-intent style. Within this style, there's merit in theorizing mechanisms as scenario-processes, with characteristic dynamics in relations among context, activity, and outcome. Now, in order to do mechanism-intent thinking well, you need to be able to think creatively and critically about context-activityoutcome dynamics. Social science theorizing about social mechanisms is helpful for that, even though such theorizing is usually geared to answering disciplinary questions in sociology.

You: That seems clear enough. Sociological theories of social processes involving social mechanisms are to be used to supplement mechanism-intent style, purposive theorizing about purposeful phenomena.

Me: That's the point. Social mechanisms analysis contributes to purposive theorizing along mechanism-intent lines and to case study research to create design-precedents.

You: It seems we still have a long way to go in this conversation.

Me: Yes, indeed! There are vistas that we haven't explored and loose-ends we haven't tied up. What do you think would be most helpful to you at this point?

You: It would be really helpful to have an example that truly illustrates what you would now consider to be a "report" on a true design-focused case study.

Me: I co-authored one over the past few years, specifically so that it would play such a role in this book.

You: Where can I find it?

Me: In the next chapter.

\section{NOTES}

1 Ravetz (1971).

2 González Asis and Woolcock (2015).

3 Jonsen and Toulmin (1988).

4 Hopp and Spearman (1996).

5 Lawson (2004).

6 Stake (1995), Ragin and Becker (1992).

7 For example, Ragin (1987).

8 Yin (2014).

9 Abbott (2001, 2004); Becker (1997).

10 Ragin (1987).

11 Hirschman (1973).

12 Skocpol (1979).

13 Allison (1971). 
14 Vaughan (2005).

15 Barzelay and Gallego (2010).

16 Lawson (2004).

17 See March (2010), Levitt and March (1988), March, Sproull, and Tamuz (1991).

$18 \operatorname{Dym}(1994)$.

19 Barzelay (2007).

20 Bardach (2004).

21 Simon (1996).

22 Van Aken and Berends (2018).

23 Barzelay and Campbell (2003).

24 Tendler and Freedheim (1994).

25 Tendler (1997).

26 Jonsen and Toulmin (1988).

27 Perrow (1986).

28 March and Simon (1958).

29 Bardach (1994).

30 Barzelay (1992).

31 Bardach (2004).

32 Hedström and Swedberg (1998).

33 Barzelay (2007).

34 Abbott $(2001,2016)$.

35 McAdam, Tarrow, and Tilly (2001).

36 Hedström (2005). 